\title{
Photocatalytic Properties of Zinc Oxide and Graphene Nanocomposites
}

\author{
Avery A. McLain \\ Physics, University of Wisconsin - La Crosse \\ La Crosse, Wisconsin, United States of America
}

\begin{abstract}
Zinc oxide $(\mathrm{ZnO})$, as a semiconducting oxide, has potential as a photocatalyst due to some of the properties it possesses, including a large excitation energy, deep violet/borderline ultraviolet (UV) absorption at room temperature, and good photocatalytic activity. However, the main issue with using $\mathrm{ZnO}$ as a photocatalyst is that it has a rapid rate for the recombination of electron-hole pairs. Since the photoactivity of a catalyst is determined by its ability to create photogenerated electronhole pairs, having a fast recombination rate can interfere with the reaction process. This issue could potentially be fixed by combining the $\mathrm{ZnO}$ with graphene, a carbon-based material. The conjugated structure of graphene enables the separation of charges in the photocatalytic process, so by combining $\mathrm{ZnO}$ and graphene the recombination rate could possibly be slowed while retaining the beneficial properties of both materials. This project analyzes the effects of $\mathrm{ZnO} /$ graphene nanocomposites on the degradation process of methylene blue dye. This dye breaks down when exposed to solar light, and so the photocatalytic properties of the nanocomposites can be studied by examining how they influence the speed of the reaction process.
\end{abstract}

\section{Introduction}

Semiconducting oxides are used as catalysts during heterogenous photocatalysis (Wang, Tsai, \& Hsieh, 1998), and the most commonly used of these oxides is the compound titanium dioxide $\left(\mathrm{TiO}_{2}\right)$ due to its low production cost and good chemical stability. Photocatalysts have many useful applications due to their abilities to influence reactions involving solar light, including uses in harvesting solar energy and helping to power space probes and satellites as a less expensive alternative to consumable fuel. However, applications of $\mathrm{TiO}_{2}$ involving solar energy are limited due to its high band gap (3.2eV) and low quantum efficiency (Wang et al, 2016). Zinc oxide (ZnO) been suggested as a potential alternative to $\mathrm{TiO}_{2}$, because although they have similar band gap energies, $\mathrm{ZnO}$ has a higher absorption efficiency across a large part of the solar spectrum (Qui et al, 2007).

Some properties of $\mathrm{ZnO}$ include a broad direct band gap width $(3.37 \mathrm{eV})$, a large excitation binding energy $(60 \mathrm{meV})$, and a deep violet/borderline ultraviolet (UV) absorption at room temperature (Choi, Kang, \& Oh, 2012), in addition to many desirable electrical, mechanical, and optical properties (Caglar, Ilican, Caglar, \& Yakuphanoglu, 2009) that make it comparable to $\mathrm{TiO}_{2}$. It has also been shown to have good photocatalytic activity (Al-Fori, Dobrestsov, Myint, \& Dutta, 2014).

The photoactivity of a catalyst is determined by its ability to form photogenerated electron-hole pairs. In the photocatalysis process, when the catalyst is photo-induced by light that has a photonic energy equivalent to or greater than the excitation energy, electrons from the filled valence band move up to an empty conduction band and leave behind holes in the valance band. These electronhole pairs can then be used in secondary oxidation-reduction reactions (Ong, Ng, \& Mohammad, 2018). 
The main problem with $\mathrm{ZnO}$ as a photocatalyst is the rapid recombination rate of the photogenerated electron-hole pairs, which disturbs the reaction process. An additional problem with using $\mathrm{ZnO}$ is that, like $\mathrm{TiO}_{2}$, its solar energy conversion performance is affected by its optical absorption ability, which is related to its large band gap energy (Ong, Ng, \& Mohammad, 2018). To increase the effectiveness of $\mathrm{ZnO}$ as a photocatalyst, a technique should be developed to extend its light absorption range or to slow the rate of the electron-hole recombination.

One potential solution to this problem would be to combine $\mathrm{ZnO}$ with a carbon-based material such as graphene. The interest in using a carbon-based material for this application is because of their unique pore structure, electronic properties, absorptive properties, and acidity. Graphene is favored over other carbon-based materials because it has an ideal $\mathrm{sp}^{2}$ hybrid carbon nanostructure and surface area (Hosseini \& Babaei, 2017). The conjugated structure of graphene allows for the separation of charges during the photocatalytic reaction process, so a combination of $\mathrm{ZnO}$ and graphene could potentially have a slower recombination rate than that of $\mathrm{ZnO}$ alone (Giem, 2009).

For this project, the photocatalytic properties of the $\mathrm{ZnO} /$ graphene nanocomposites were studied by examining their effect on the degradation of methylene blue (MB) dye, which breaks down when exposed to solar light. The objectives were to examine the photocatalytic properties of $\mathrm{ZnO}$ and graphene nanocomposites formed by ultrasonic homogenization, to compare these properties to those of $\mathrm{ZnO}$ or graphene alone, and to measure changes in the concentration of $\mathrm{MB}$ dye relative to the exposure time for UV irradiation in order to gain information about the degradation process of $\mathrm{MB}$ with the $\mathrm{ZnO} /$ graphene nanocomposites as photocatalysts.

Similar research on the photocatalytic properties of $\mathrm{ZnO} /$ graphene nanocomposites was done by A. R. Nanakkal and L. K. Alexander at the University of Calicut in India, where they studied the properties of nanocomposites fabricated using an electrochemical method (Nanakkal \& Alexander, 2017). Other related studies include the research done by Gayathri et al on $\mathrm{ZnO} /$ graphene nanocomposites synthesized using a simple chemical precipitation method (Gayathri, Jayabel, Kottaisamy, \& Ramakrishnan, 2014), and the research of Seyed A. Hosseini and Shabnam Babaei at Urmia University in Iran, on nanocomposites fabricated by ultrasonication using ethanol, methanol, and chloroform, precipitation, and freeze-drying (Hosseini \& Babaei, 2017).

\section{Materials and Methods}

For this experiment, $\mathrm{ZnO}$ powder and graphene nanoplatelets were purchased from Alfa Aesar. The nanocomposites of $\mathrm{ZnO} /$ graphene were formed using two different methods: one type was created using ultrasonic homogenization and the other type was formed by chemically reacting the $\mathrm{ZnO}$ and graphene in a furnace. The nanocomposite formed using the second method was created by Dr. Dan Little from the University of Wisconsin - La Crosse's department of chemistry. This nanocomposite is a synthesized material made from graphene and zinc(II) oxalate with a 10:1 mole ratio of carbon to zinc. At high temperatures the zinc(II) oxalate decomposes into $\mathrm{ZnO}$ and $\mathrm{CO}_{2}$ so this nanocomposite was created in an attempt to cause the $\mathrm{ZnO}$ to chemically insert itself into the structure of graphene, instead of just mixing them.

Separately, $\mathrm{ZnO}$, graphene, and both types of nanocomposites of $\mathrm{ZnO} /$ graphene were mixed with 
$0.05 \mathrm{~g} / \mathrm{L}$ methylene blue dye $(\mathrm{MB})$ and $50 \mathrm{~mL} \mathrm{H}_{2} \mathrm{O}$. Each of these dispersions were sonicated for 15 minutes at $15 \%$ power. They were then placed under a solar simulator for 1.5 hours, and a portion of each dispersion was removed every 15 minutes. These portions were centrifuged at $4000 \mathrm{rpm}$ for 20 minutes to remove any excess particles and separate out the liquid, and then the liquid was analyzed in a UV-Vis Spectrometer in order to collect absorbance data. This data was plotted in SciDaVis to show the changes in MB concentration relative to exposure time, and to compare the differences between the photocatalytic abilities of the nanocomposites in each of the different dispersions.

\section{Key Results}
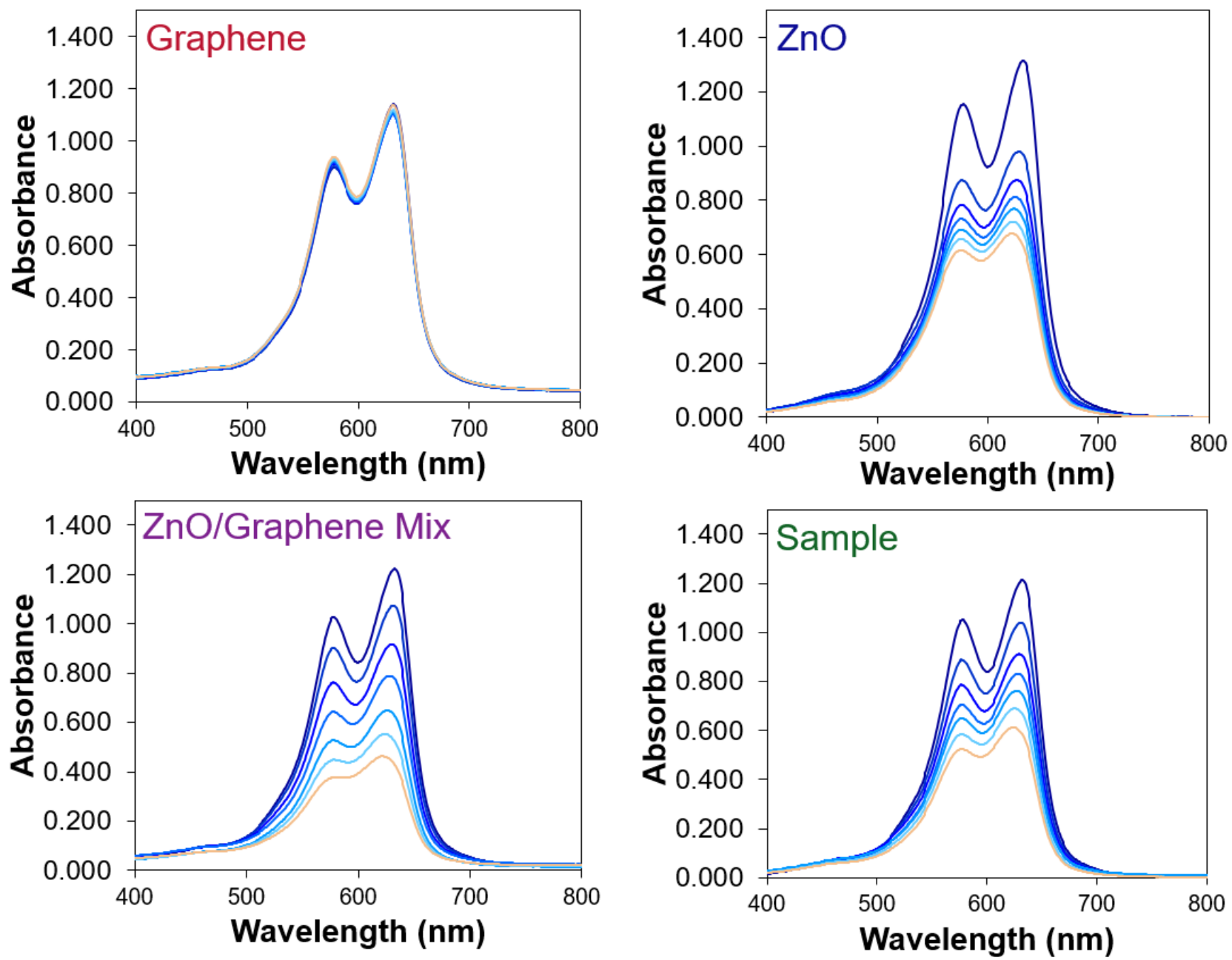

Figure 1: The absorbance data collected during the dispersions' 1.5-hour exposure to the solar simulator

The top two graphs show how graphene and $\mathrm{ZnO}$ alone affected the degradation process for $\mathrm{MB}$, using $0.0057 \mathrm{~g} / \mathrm{L}$ graphene and $0.043 \mathrm{~g} / \mathrm{L} \mathrm{ZnO}$ respectively. The bottom graphs show the nanocomposite formed by mixing the graphene and $\mathrm{ZnO}$ and then sonicating them together (left) 
and a sample of the nanocomposite synthesized in the lab using a furnace (right). Both contain the same amounts of $\mathrm{ZnO}$ and graphene as used for the individual tests.

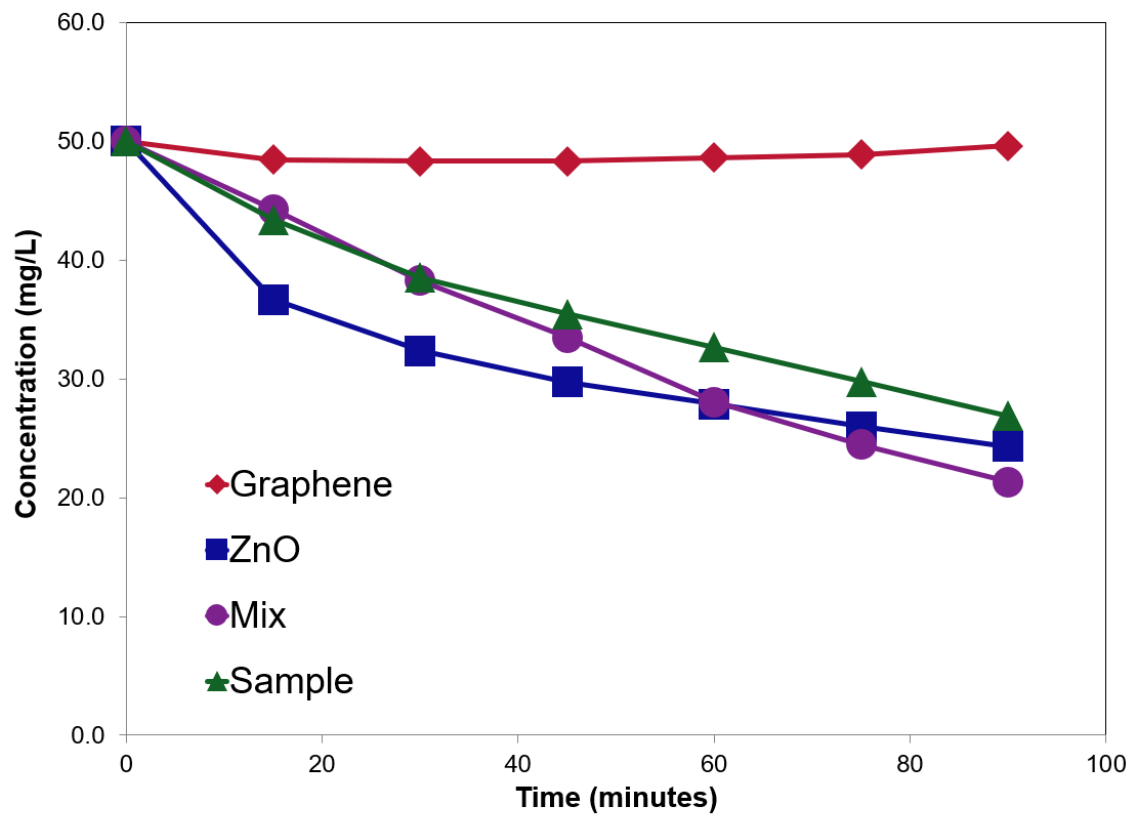

Figure 2: A comparison of the rates of change of the concentrations of MB dye during the 1.5-hour solar exposure, for each of the different materials used as photocatalysts

In order to better compare the different capabilities of each of the materials used as photocatalysts, the changes in the amount of MB over time were calculated for each material, and then plotted together to show how each material affected the degradation of MB during the exposure period.

\section{Discussion}

The different rates at which the MB degraded shows the different ways in which each of the materials used impacted the degradation process and demonstrates the potential of each material as a photocatalyst. As expected. Graphene alone does not have the potential to be an effective photocatalyst. $\mathrm{ZnO}$, the nanocomposite formed by sonicating a mixture of $\mathrm{ZnO} /$ graphene, and a sample of the nanocomposite created in a furnace all degraded a similar amount of MB at the end of the 1.5-hour exposure period, as illustrated by Figure 2. However, an interesting thing to note about this is that even though these materials had degraded comparable amounts of MB by the end of the exposure period, each material had a different rate of change over the 1.5 hours. $\mathrm{ZnO}$ alone had a sharp initial decrease in the amount of $\mathrm{MB}$, but then the rate of change became less steep after that. The mix and the sample both start with similar rates of changes, but then around the 30minute mark the rate of the sample decreases while the rate of the mix stays the same. This helps to show how different methods of fabrication can affect the properties of the nanocomposite that is formed, and further study of the different methods of fabricating $\mathrm{ZnO} /$ graphene nanocomposites could help determine which fabrication method is best for making more efficient photocatalysts. 
This connects to the other research mentioned earlier of other scientists studying the photocatalytic properties of their nanocomposites, which were created using a variety of methods including an electrochemical method and chemical precipitation.

\section{Acknowledgements}

This research would not have been possible without funding from the Wisconsin Space Grant Consortium, and I am grateful to them for their support of my work. I would also like to thank my mentor Dr. Seth King for his guidance and advice, as well as for the use of his lab space. Additionally, I would like to thank Dr. Dan Little for allowing me to use the nanocomposite that he created for my research and for all of his assistance throughout the course of this project. Likewise, I am grateful to Jake Pfund and Dr. Taviare Hawkins for their encouragement and support. Finally, I would like to thank the University of Wisconsin - La Crosse for helping me to have this opportunity.

\section{References}

1. Al-Fori, M., Dobrestsov, M., Myint, M. T., \& Dutta, J. (2014) Antifouling properties of zinc oxide nanorod coatings. Biofouling: The Journal of Bioadhesion and Biofilms Research, vol. 30 no. 7, p. 871-882. DOI: https://doi.org/10.1080/08927014.2014.942297

2. Caglar, M., Ilican, S., Caglar, Y., \& Yakuphanoglu, F. (2009) Electrical conductivity and optical properties of ZnO nanostructured thin film. Applied Surface Science, vol. 255 no. 8, p. 4491-4496. DOI: https://doi.org/10.1016/j.apsusc.2008.11.055

3. Choi, K., Kang, T., \& Oh, S. G. (2012) Preparation of disk shaped ZnO particles using surfactant and their PL properties. Materials Letters, vol. 75, p. 240-243. DOI: https://doi.org/10.1016/j.matlet.2012.02.031

4. Gayathri, S., Jayabel, P., Kottaisamy, M. \& Ramakrishnan, V. (2014) Synthesis of ZnO decorated graphene nanocomposite for enhanced photocatalytic properties. Journal of Applied Physics, vol. 115. DOI: https://doi.org/10.1063/1.4874877

5. Giem, A. K. (2009) Graphene: Status and Prospects. Science, vol. 324. DOI: http://doi.org/10.1126/science.1158877

6. Hosseini, S. A., \& Babaei, S. (2017) Graphene Oxide/Zinc Oxide (GO/ZnO) Nanocomposite as a Superior Photocatalyst for Degradation of Methylene Blue (MB) Process Modeling by Response Surface Methodology (RSM). Journal of the Brazilian Chemical Society, vol. 28 no. 2, p. 299-307. DOI: http://dx.doi.org/10.5935/0103$\underline{5053.20160176}$

7. Nanakkal, A. R. \& Alexander. L. K. (2017) Photocatalytic Activity of Graphene/ZnO Nanocomposite Fabricated by Two-step Electrochemical Route. Journal of Chemical Sciences, vol. 129, p.95-102. DOI: http://doi.org/10.1007/s12039-016-1206-X 
8. Ong, C. B., Ng, L. Y., \& Mohammad, A. W. (2018) A review of ZnO nanocomposites as solar photocatalysts: Synthesis, mechanisms, and applications. Renewable and Sustainable Energy Reviews, vol. 81 part 1, p. 536-551. DOI: http://dx.doi.org/10.1016/j.rser.2017.08.020

9. Qui, R., Zhang, D., Mo, Y., Song, L., Brewer, E., Huang, X., \& Xiong, Y. (2007) Photocatalytic activity of polymer-modified $\mathrm{ZnO}$ under visible light irradiation. Journal of Hazardous Materials, Vol. 156, p. 80-85. DOI: https://doi.org/10.1016/j.jhazmat.2007.11.114

10. Wang, A.N., Teng, Y., Hu, X.F., Wu, L. H., Huang, Y. J., Luo, Y. M., \& Christie, P. (2016) Diphenylarsinic acid contaminated soil remediation by titanium dioxide (P25) photocatalysis: Degradation pathway, optimization of operating parameters and effects of soil properties. The Science of the Total Environment, vol. 541, p. 348-355. DOI: https://doi.org/10.1016/j.scitotenv.2015.09.023

11. Wang, K. H., Tsai, H. H., \& Hsieh, Y. H. (1998). A study of photocatalytic degradation of trichloroethylene in vapor phase on $\mathrm{TiO}_{2}$ photocatalyst. Chemosphere, vol. 36 no. 13, p. 2763-2773. DOI: https://doi.org/10.1016/S0045-6535(97)10235-1 